\title{
Tales of Wonder: Retelling Fairy Tales through Picture Postcards
}

by Jack Zipes, with a foreword by Marina Warner

Minneapolis: University of Minnesota Press, 2017, 223 pages

ISBN 978-1-5179-0259-9 (hardback) Price \$34.95

Reviewed by Annebella Pollen, University of Brighton, UK

From their first appearance as new postal technologies in the late nineteenth century to their developments as carriers of innovative pictorial printing in the early decades of the twentieth century, postcards offered a cheap and attractive means of fast communication that spread worldwide. Necessitating brevity of text, and circulating in their millions at their peak with multiple deliveries per day, postcards were abundant, high-speed and enormously popular. The images that they carried varied widely, and were far more extensive than those visible in the few postcards that cling on in our email and text-message dominant age, where they largely continue only as tourist souvenirs at seaside resorts, advertising messages from product promoters, or cheap reproductions of artwork in museum gift shops. At the turn of the twentieth century, postcards covered an extraordinary range of visual culture, and their collectors and enthusiasts - deltiologists, in their own parlance - often specialise in particular sub-genres of the form, from 'real photo' cards featuring mostly studio portraiture, the illustrative work of particular practitioners or favoured themes, from transportation to topography.

Jack Zipes, most widely known as the pre-eminent scholar of fairy tales as a literary form, has been collecting postcards of fairy tales from around the world for the same half-century that he has been scrutinising the tales themselves. This activity initially provided a 
pleasurable adjunct to his scholarly work, and he speaks keenly of his frequent trips to flea markets and antiquarian bookshops (and also apologises to his immediate family for having to endure these excursions too). The amassed 2500 cards that make up Zipes' collection had to wait until his retirement from university life to submit to his organisation and publication; this work finally takes form in the book Tales of Wonder. The result is a lavish, heavyweight volume, measuring some $32 \mathrm{~cm} \times 32 \mathrm{~cm}$, with high quality and full colour reproductions throughout. For the humble, cheap and often poorly-produced postcards within its pages, this represents a significant scaling-up of value and status.

Zipes argues that the fairy tale picture postcard has been neglected as a standalone site of study, despite the cards' evident abundance in a range of styles from a range of global locations since the late nineteenth century. One might argue that the almost infinite subcategories within the postcard's purview means that the fairy tale postcard is no more significant than any of the other subcategories, from images of rough seas to motor car crashes (to name but two of the popular subjects for postcards in the early twentieth century). Zipes argues, however, that fairy tales on postcards demonstrate in their form a significant manifestation of the act of storytelling; each picture postcard image is necessarily a retelling of a tale that is ever remade as it circulates. The ways that postcards 'have wings', in his words, traversing across national borders, gives them a further poetic parallel with fairy tales. His selected cards definitely demonstrate enduring engagements with fairy tales in popular culture across different periods and times (500 cards are included, covering around 130 years, from locations including Europe, Asia, America and, notably, Russia). The book is structured curiously. It begins with an elegant foreword from Marina Warner, who appraises Zipes' significant contribution to the wider study of myth, and makes some deft 
interpretations of the cultural value of his postcards. Zipes then orders his cards around particular tales, reproducing original texts alongside, for example from Charles Perrault, as accompaniment. Zipes' commentary on these sections says far more about the origins and shifting uses of the tales than it does about the cards that depict them; their style and visual message are summarised rather bluntly, if discussed at all. The 'reading' of individual cards is frustratingly absent, save for a section, strangely deferred, entitled 'The Art', towards the end of the book. Here named illustrators - some little-known - and selected series of cards are given dedicated spreads, but here discussion is also paltry; despite the sometimes complex illustrations and the highly choreographed tableaux of the photographic series, mostly the images are left to speak for themselves. To be fair, Zipes is not an art historian but this omission is a great shame in a book that is so image-led, and where the avenues for interpretation seem so fertile. As Zipes argues, the cards each offer a retelling of a tale for a particular time and a particular audience, but what the retelling might mean is left unsaid.

One only has to look at the range of different meanings applied to the huge variety of retellings of Red Riding Hood in picture postcard form, to give but one example, to see how shifting ideas about childhood, nature, sex, age, fear and gender are mobilised visually for different purposes at different times. In an illustrated example from France in the 1950s, the wolf's lascivious gaze aims directly at the exposed décolletage of a red-hooded maiden with a come-hither expression and a rose between her breasts. Another highly sexualised American interpretation from the 1920 s shows, in crude greetings card cartooning, the wolf driving a convertible car and attempting to pick up a pneumatic young woman at the kerbside with a whistle and a call: 'Goin' my way?' Elsewhere Red Riding Hood is pictured as little more than an infant, cherubic of features, but she can also appear hardnosed in depictions that graphically show the spurting blood of her slaughtered enemy. In each case, the clothes, the settings and the stylings could tell us so much about artist and audience, about producer and consumer, about style and taste, but none of this is provided. 
Perhaps my principal frustration with this nonetheless beautiful book is that there is no discussion of the ways that specific cards were sent and received. Clearly many are used examples as in some cases stamps are visible and in others dates are provided in the captions based on the postmarks. Some are definitely inscribed, as text is visible alongside the images in the early examples when the backs of postcards were reserved for addresses only. Zipes provides two fascinating clusters of images of tales being told on postcards, which is much less literal than images of fairy tales. These take the form of raconteurs and their audiences, variously illustrated and photographed, showing yarns being spun at hearths and bedsides and in street gatherings worldwide. In one American example from 1909, a black man tells a tale to two rapt children on benches in a yard. The sender has scribbled in pencil below: 'How would you like to hear the story / I think it must be a good one'. Strangely, despite this tantalising glimpse at how the cards were engaged with, there's no acknowledgement in the book of the fact that postcards are themselves vernacular communicative devices. These cards each carry small stories of their own on their reverse, but these are never shown, much less discussed. Warner, in her introduction, makes the excellent point that 'postcards are the inheritors of the Renaissance medal, their two sides forming a third, unvoiced meaning' (viii). In showing us only the image side, Zipes' extraordinary collection, for all its scale and spectacle, tells us less than half the tale. 